World Applied Sciences Journal 21 (Special Issue of Studies in Language Teaching and Learning): 50-56, 2013 ISSN 1818-4952

(C) IDOSI Publications, 2013

DOI: 10.5829/idosi.wasj.2013.21.stt1.2137

\title{
The Effects of Internet-assisted Language Learning (IALL) on the Development of ESL Students' Critical Thinking Skills
}

\author{
${ }^{1}$ Faizah Mohamad and ${ }^{2}$ Nuraihan Mat Daud \\ ${ }^{I}$ Academy of Language Studies, Universiti Teknologi MARA (UiTM) \\ ${ }^{2}$ Kulliyyah of Languages and Management, International Islamic University Malaysia
}

\begin{abstract}
The primary concern of the present research was to investigate the effects of an Internet-Assisted Language Learning (IALL) environment on the development of L2 students' critical thinking skills. A total of 77 students of Diploma in Hotel Management at UiTM Terengganu, Dungun Campus, Malaysia were involved in this study. This sample was divided into three groups, namely full, partial and non-IALL environments. Cornell Critical Thinking Test (CCTT), Level X, was administered as the pre-post-test to measure the development of L2 students' critical thinking skills. The CCTT scores revealed that students who were exposed to the full IALL environment improved significantly in their critical thinking skills as compared to those in the partial and non-IALL environments. When the various sub-skills were measured, the analysis showed that they improved the most in the connecting skill, an element of the higher order thinking skills. The present study concludes that using the Internet in language classrooms helps to create critical ESL students.
\end{abstract}

Key words: Internet-Assisted Language Learning (IALL) \%Critical thinking skills \%Cornell Critical Thinking Test (CCTT) \%Connecting skill \%Higher order thinking skills

\section{INTRODUCTION}

Numerous definitions have been given to critical thinking skills [1]. According to [2], critical thinking is the systematic attempt to think about thinking which involves recognizing how it functions, evaluating its strengths and weaknesses and restructuring it in order to improve it. "It is thinking about your thinking while you're thinking in order to make your thinking better" [3] (p. 1). In other words, thinking is to improve thinking. [4] explain that the nature of critical thinking which focuses on "questioning premises and unpacking assumptions can be understood as deepening the space of dialogue". [5] states that critical thinking used to be in the realm of philosophy or literature studies, but it now emphasizes the mental attitudes or "dispositions" and the application of reasoning to everyday situations. She also posits that critical thinking shares common features across the disciplines. They are:

C Critical thinking can be learned with teachers and peers serving as resources.
C Problems, questions and issues will be the source of motivation for the students.

C Courses are based on assignments rather than text or lecture.

C Goals, methods and evaluation focus on using content instead of simply acquiring it.

C Students have to formulate and justify their ideas in writing.

C Students learn collaboratively as to enhance their thinking.

[5] (p.3)

These easy-to-implement ideas are applicable to the online setting and in this research, it is called Internet-Assisted Language Learning (IALL) environment. In this environment, language teachers are expected to focus on teaching the process of discovery learning within the students' own contextual meaning instead of on individual mastery of the language and the product of language competency.

Corresponding Author: Faizah Mohamad, Academy of Language Studies, Universiti Teknologi MARA (UiTM), Malaysia. 
Critical Thinking in Malaysian Education: The Malaysian education emphasizes the transmission of knowledge, which is delivered by the teachers. Teachers normally play the role of instructors rather than facilitators. Learning is a passive process. It focuses less on critical thinking development and students rarely challenge the views held by their teachers [6]. The recent focus on outcome-based education by the Malaysian Ministry of Education is slowly changing the scenario. Teachers are urged to integrate critical thinking skills into their curriculum. Hence, there is a need to look at the possible ways of improving students' thinking skills in some subject-specific disciplines. This paper aims to determine how such a skill is developed in a computerassisted language learning class.

To understand the difficulty of developing students' critical thinking skills, one needs to consider the students' background culture. According to [7], Malaysian culture, which stresses on 'proper attitude' and 'obedience' might turn the students into passive learners. Children are taught to respect their teachers and it is considered improper to challenge the teachers. [8] describes Malaysian students as passive and the curious, questioning students are the exception rather than the rule in the classrooms. Furthermore, the examinationoriented system tends to encourage students to read and memorize rather than to think critically in order to perform well in the examinations $[6,7,9]$. Teachers are more concerned about the students' performance in the final examination rather than their engagement in the learning process [10]. Realizing this problem, the Malaysian Education Ministry has taken steps in rectifying this problem by, first, introducing a new examination format which emphasizes more on critical thinking.

It is a well-known fact that the Internet is a powerful means of communication and it has become an ever growing resource for English language teachers and students. It has also been commonly believed that the Internet can remarkably improve learners' learning experiences [11]. Thus, the government introduced the Smart Schools project in 1999 with plans to integrate the use of computer technology in the teaching and learning process. The project was hoped to produce Malaysians who are innovative in their thinking and adept at using new technologies [12]. Even though most schools in Malaysia are equipped with computers, the how of integration is still a major issue. Many teachers are still vague about integrating technology into the curriculum $[13,14]$. This study is thus conducted to determine whether Internet-Assisted Language Learning (IALL) environment can foster students' critical thinking skill. The study investigates how the Internet environment helps to develop language students' critical thinking skills.

Research Questions: This research attempts to discover whether IALL environment affects the development of ESL students' critical thinking skills. The research questions are as follows:

C Will students in full IALL environment (experimental group 1) develop critical thinking better than those in partial IALL environment (experimental group 2) and those in non-IALL environment (control group)?

C Will the amount of time spent in IALL environment affect L2 students' critical thinking development?

C Do the different environments have any effect(s) on the development of critical thinking sub-skills of connecting, evaluating and analysing?

\section{MATERIALS AND METHODS}

Research Design: A quasi-experimental design was used to determine the effects of IALL environment on critical thinking development. The most common quasiexperimental design is the Comparison Group Pre/Post Test design. This design is the same as the classic controlled experimental design except that the subjects cannot be randomly assigned to either the experimental or the control group, or the researcher cannot control the timing or nature of the treatment [15].

The design for this research can be diagrammed as follows:

$\begin{array}{lll}\mathrm{O}_{1} & \mathrm{X}_{1} & \mathrm{O}_{2}-\text { Experimental Group A } \\ \mathrm{O}_{1} & \mathrm{X}_{2} & \mathrm{O}_{2}-\text { Experimental Group B } \\ \mathrm{O}_{1} & & \mathrm{O}_{2}-\text { Control Group }\end{array}$

$\mathrm{O}_{1}$ - pretest,

$\mathrm{O}_{2}$-post-test,

$\mathrm{X}_{1}$ - Treatment 1 ,

$\mathrm{X}_{2}$ - Treatment 2

The independent variable for this research was the environment, a variable with three categories: a full IALL environment, a partial IALL environment and a non-IALL environment. The dependent variable was the difference between the pre-test and post-test scores. The test was Cornell Critical Thinking Test (CCTT), Level X. 
The Instrument: To determine the development of critical thinking skill, Cornell Critical Thinking Test (CCTT), Level $\mathrm{X}$ developed by [16] was used as the instrument. This test had 71 questions and the participants had to respond to one of the three alternatives given for each question. Since the participants were in their second semester of a diploma course, this instrument was the most appropriate as it was suitable for beginning college students. Furthermore, the participants were non-native speakers who had mixed levels of proficiency. [17] recommended that this level be used for those who were less sophisticated in their English language ability. Using the "Spearman-Brown" and "Kuder-Richardson" methods of testing reliability, this test had the reliability estimates ranging from.67 to. 90 [17].

The Coverage of Cornell Level X: This test was a general critical thinking test to assess the students' critical thinking abilities that covered critical thinking skills namely induction, deduction, observation, credibility and assumptions. It did not call for any value judgements that might cause the students to be discredited or penalized for any political, economic or social values they hold. The Cornell Level X sought to investigate the students' ability to judge whether:
C "A statement follows from the premise;
C Something is an assumption;
C An observation statement is reliable;
C An alleged authority is reliable;
C A simple generalization is warranted;
C A hypothesis is warranted;
C A theory is warranted;
C An argument depends on an ambiguity;
C A statement is overly vague or overly specific;
C A reason is relevant"

Students are expected use their reasoning and analytical abilities, ignoring their conception of how things were. Answers are be based on the evidence given. The context of the test is a story about a group of explorers who landed on another planet with a mission to find out what happened to the first group of explorers who landed on the planet two years earlier. The students are to imagine that they are the members of the search party and to make decisions based on the information given in each paragraph.
Scoring the Cornell Critical Thinking Test: There are two ways of scoring the test:

C "Right" scores in which only the correct number of responses are be counted; and

C "Weighted" scores in which the formula right minus one-half number wrong is applied. This is to discourage test-takers from making wild guesses.

Since students in this study were familiar with obtaining marks when answering questions correctly the researcher used the "Right" only method in scoring the test.

Participants: The participants of the study consisted of 77 students following Diploma in Hotel Management (DHM) programme at MARA University of Technology, Dungun branch. They were in the second semester of the programme. This group was chosen for the following reasons:

C The English language s yllabus was appropriate for this study because it covered expository and argumentative writing and group discussions.

C The students' schedules were packed with practical courses at the hotel. This would somehow refrained the students from spending their free time at the Internet lab or exchanging information on what went on in any of the classes under study which might influence the outcomes. This implies that whtever changes or improvements made, they are due to the intervention programme.

C Though these students might have the computer skills, they did not have any other computer-related courses that semester. This means that they are exposed to the Internet only in this course.

Language Learning Environments: The research involved three groups, each experiencing one of the following environments:

Group A (Experimental Group): The learning environment was non-traditional and Internetbased instructional materials were used for 6 hours per week. There were 28 students in this group and they were required to have a YAHOO account. 
YAHOO MESSENGER was used for discussions. For board discussions, the researcher registered the class with NICENET. This allows them to share ideas and to discuss the topic posted by the teacher cum researcher. The teacher made herself accessible to the students in the computer lab whenever they were unclear about the instruction given to them. Most of the time, the students did the assigned work independently, with minimum interference from the teacher. The students were also free to walk about in the lab, to ask their friends questions and to discuss the topic at hand. Once the students completed the given task, they were encouraged to surf the Internet to look for other language exercises or activities related to the topic given.

Group B (Experimental Group): The learning environment was both traditional and non-traditional where both Internet-based instructional materials and printed materials were used. There were 23 students in this group. Since the group was exposed to a partial IALL environment, the students were also required to open a YAHOO account. Discussions were also conducted via YAHOO MESSENGER and the researcher also registered this group with NICENET for board discussions. This group went through the same process as Group A, but they spent only 2 hours per week in the computer lab. The other 4 hours were conducted in a regular class where the traditional chalk and talk method was used. The students were required to participate in both Internet-based and face-to-face discussions.

Group C (Control Group): The learning environment was fully traditional, utilizing printed materials and oral, face-to-face interaction. There were 26 students in this group and they were in the regular classroom instead of the Internet lab. The mode of instruction was chalk and talk for 6 hours per week. They were not exposed to the IALL environment.

The materials used in all the classes were the same and they were retrieved from the Internet. However, in the non-Internet environment, these materials were downloaded for the students.

Procedures of Data Collection: The treatment took 14 weeks. Before the treatment began, all groups were asked to complete a pre-test to asses students' level of critical thinking skills and also the initial equivalence among groups. The materials used to teach each group were based on the same syllabus. Thus, there were no discrepancies in the contents of the instruction. Since training other teaching staff to teach this course would be time-consuming, the researcher who was one of the staff, taught all the three groups herself. This also helped to control teacher variable. At the end of 14 weeks, the groups were given a post-test and the difference between the pre and post-tests were noted for data analysis. The test was a standard test in which the students had to complete in one hour. The level of significance was set at 0.05 for this research.

Data Analysis: Standard statistical procedures were used to analyze the data. One-way ANOVA tests were conducted on the difference of scores in pre and posttests for the overall skills and on the difference of scores for each individual sub-skill in the test.

\section{RESULTS}

This section presents the findings obtained from the analyses on the differences of scores of the Cornell Critical Thinking Test.

The Overall Development: In order to test the initial equivalence among groups, a one-way ANOVA test was run on the results of the pre-test. Table 1 shows that there was no significant difference among the three groups: $F(2,74)=1.730, p>0.05$. Thus, it could be safely said that the critical thinking ability of the students in each group before the treatment was given was the same.

After the treatment, a post-test was given and the one-way ANOVA test was run on the difference scores of the pre and post-tests (post test scores minus pre-test scores). The results for the overall development of the critical skills in Table 2 showed that there was a significant mean difference in the scores among the three groups: $\mathrm{F}(2,74)=3.994, \mathrm{p}<0.05$.

Although the significant $F$ value was found, it did not indicate which means were different from each other. Hence a post hoc multiple comparison test was run. The post hoc Fisher's LSD (Least Significant Difference) indicated that the students' in full IALL environment scored better on the overall critical thinking skills than those in partial IALL environment (Fisher' $s=2.71, p<0.05$ ) and than those in non-IALL environment (Fisher' $\mathrm{s}=3.15$, $\mathrm{p}<0.05)$. 
Table 1: One-way ANOVA for the Pre-Test

\begin{tabular}{lllllll}
\hline & & Sum of & & Mean & & \\
& & Squares & df & Square & F & Sig. \\
\hline PRE-TEST & Between Groups & 147.670 & 2 & 73.835 & 1.730 & .184 \\
& Within Groups & 3157.421 & 74 & 42.668 & & \\
& Total & 3305.091 & 76 & & & \\
\hline
\end{tabular}

Table 2: A One-way Analysis of Variance Comparing the Means of the Difference in CCTT Pre- and Post-test Scores across the Three Groups

\begin{tabular}{llllll}
\hline & $\begin{array}{l}\text { Sum of } \\
\text { Squares }\end{array}$ & df & $\begin{array}{l}\text { Mean } \\
\text { Square }\end{array}$ & F & Sig. \\
\hline Between Groups & 156.798 & 2 & 78.399 & 3.994 & .023 \\
Within Groups & 1452.422 & 74 & 19.627 & & \\
Total & 1609.221 & 76 & & & \\
\hline
\end{tabular}

Table 3: The mean differences among the skills.

\begin{tabular}{llll}
\hline IALL Environment & & & \\
Full & Connecting & Evaluating & Analyzing \\
\hline Mean & 2.18 & 1.11 & .50 \\
$\mathrm{~N}$ & 28 & 28 & 28 \\
Std. Deviation & 3.92 & 2.47 & 1.75 \\
\hline Partial & & & \\
Mean & -.17 & -.17 & 1.09 \\
N & 23 & 23 & 23 \\
Std. Deviation & 3.52 & 2.61 & 1.62 \\
\hline Non & & & \\
Mean & $8.33 \mathrm{E}-17$ & $3.85 \mathrm{E}-02$ & .27 \\
$\mathrm{~N}$ & 26 & 26 & 26 \\
Std. Deviation & 3.43 & 2.44 & 1.61 \\
\hline Total & & & \\
Mean & .74 & .36 & .60 \\
N & 77 & 77 & 77 \\
Std. Deviation & 3.76 & 2.53 & 1.68 \\
\hline
\end{tabular}

Table 4: ANOVA tests for the Three Sub-skills

\begin{tabular}{lllllll}
\hline \multirow{2}{*}{ Source } & $\begin{array}{l}\text { Dependent } \\
\text { Variable }\end{array}$ & $\begin{array}{l}\text { Type III Sum } \\
\text { of Squares }\end{array}$ & df & $\begin{array}{l}\text { Mean } \\
\text { Square }\end{array}$ & F & Sig. \\
\hline ENVIRON Connect & 91.394 & 2 & 45.697 & 3.446 & .037 \\
& Evaluate & 24.874 & 2 & 12.437 & 1.988 & .144 \\
Analyze & 8.578 & 2 & 4.289 & 1.541 & .221 \\
\hline
\end{tabular}

Amount of Time: The result above also revealed that the amount of time spent in the IALL environment made a difference as the students who spent 6 hours in the IALL environment developed better critical thinking skills than those who spent 2 hours and 0 hours in the IALL environment. The finding also showed that there was no significant mean difference in the scores of the partial and non-IALL groups (Fisher's $=.44, \mathrm{p}>0.05$ ). This strengthened the fact that the amount of time spent did have an effect on critical thinking development: the more time spent in the IALL environment, the better the development of critical thinking skills.
The overall mean difference for each sub-skill is presented in Table 3.

From this table, we could conclude that the full IALL environment group had the highest mean score in connecting skill as compared $(\mathrm{M}=2.18)$ to the other skills within the group and among the groups. The group also scored the highest mean difference for evaluating skill (1.11). In the analyzing skill, however, the full IALL environment group scored lower than the partial IALL environment group $(M=.50)$. As for the partial IALL environment, the improvement was only present in the analyzing skill (1.09), but not in the evaluating (-.17) and connecting skills (-.17). It seems that this group scored the highest in analyzing skill among the three skills within the group and also among the three groups. The nonIALL environment also experienced very minimal improvements in evaluating and analyzing skills (0.04 and 0.26 respectively) and no improvement was shown in connecting skill (nearly 0.00).

In order to see if there were differences in the mean in each sub-skill, ANOVA tests were run. The results of the tests were shown in Table 4.

Sub-Skill I-Connecting: Table 4 displays that there was a statistically significant mean difference among the three groups for this skill: $F(2,74)=3.446, p<0.05$. Again, the post hoc Fisher's indicated that the students in the full IALL environment scored better than the students in the partial and non-IALL environments (Fisher's= 2.35, $\mathrm{p}<0.05$ and Fisher's $=2.18, \mathrm{p}<0.05$ respectively). It was also found that there was no significant mean difference found between them (Fisher's=.17, p>0.05).

Sub-Skill II-Evaluating: ANOVA test indicated that there was no significant mean difference found among the three groups for this skill: $\mathrm{F}(2,74)=1.988$, $\mathrm{p}>0.05$. Thus, the IALL environment did not have an effect on the development of this sub-skill.

Sub-Skill III-Analyzing: There was no significant mean difference found among the three groups for this skill: $\mathrm{F}(2,74)=1.541, \mathrm{p}>0.05$. Thus, the IALL environment did not affect the development of this sub-skill.

\section{DISCUSSIONS}

The students in the full IALL environment developed their critical thinking skills better than those in the other two environments. The findings indicated that the full IALL environment created in the research was able to 
enhance students' critical thinking skills better than those in the partial and non-IALL environments. The IT environment made language learning more meaningful, thus encouraging the students to think more critically in their language learning process. IALL environment enabled the students to practice using the language as they worked on the Internet collaboratively and independently. Nevertheless, to make IALL environment more effective in the development of critical thinking skills, additional time would need to be spent in the environment. This research showed that the longer the time spent in IALL environment the more critical were the students.

The findings also reflected that the students in the full IALL environment developed the connecting skill better as compared to those in other environments. This could be attributed to the activities conducted in the full IALL environment, such as online forums and board discussion where the students had to share their ideas and respond to their friends' comments. [19] confirms that regular on-line discussions could promote critical thinking development. The activities allowed them to argue on a topic without any reservations or feeling embarrassed or afraid since the argument was not done face-to-face. The students were able to relate their ideas to others' more easily and to revise them as they were presented in written form. In classes where the mode of discussion was face-to-face, the students seemed to have problems in recalling the ideas presented by their friends. Online exercises could also be a contributory factor to the development of this skill as they gave the students the opportunity to practice using the language. Moreover, the immediate feedback given by the computers made it more convenient for them to learn from their mistakes [20]. The combination of features that was created in the full IALL environment provided the opportunity to enhance the development of this skill.

Although there were no significant developments in the other two skills (evaluating and analyzing), there were still improvements for these skills in the full IALL environment group. The mean scores for evaluating and analyzing skills improved from 10.68 to 11.79 and from 4.46 to 4.96 respectively. The fact that the difference in the mean score for evaluating skill was the highest for this group (1.11) indicates that this skill has the potential to be further developed in the Internet environment. The overall results of each sub-skill also revealed that there was a regression in terms of connecting and evaluating skills for the partial IALL environment and there was almost no improvement in similar skills for the non-IALL environment.
The Importance of Research to Language Teacher: The findings show that the use of the Internet in language classrooms can help to develop students' critical thinking skills. [21] claims that "the domain of the online course environment may demand even higher levels of critical thinking disposition and skill than traditional classrooms" (p.72). The results also revealed that the IALL environment, which offered a variety of activities such as online exercises and forum discussions, can be a useful platform to mould critical ESL students. They can help students practice critical thinking in this environment without overtly explaining the goals of the exercise. The two (language and critical thinking) need not be tackled separately in a language class.

The Internet has an abundance of resources for students to learn. [22] asserts that the Internet offers more learning opportunities for both teachers and students to explore as compared to the traditional classroom environment. The use of technology also calls for a change of role from information transmitter to a facilitator. Ultimately the IALL environment enables and encourages the students to be responsible for their own learning.

\section{CONCLUSION}

From this research, it can be concluded that using the Internet in a language classroom can help develop ESL students' critical thinking skills. Students in the full IALL environment developed their critical thinking skills in particular connecting skill, better than those in the other two environments. Furthermore, the more time spent in the IALL environment, the better the development of their connecting skills. The IALL environment encourages the students to take the roles of a critic especially in the articulation and sharing of ideas. This in itself leads to better thinking. The IALL environment serves to show that both language and critical thinking skills could be developed within the language curriculum. It illustrates how the technology can be integrated effectively in a language classroom.

\section{REFERENCES}

1. Özkahraman, Sükran and Demirel, Süleyman, 2011. An Overview of Critical Thinking in Nursing and Education, American International Journal of Contemporary Research, 1(2): 190-196.

2. Christopher, B., 1998. Critical thinking skills: An interview with Dr. Richard Paul. Word's Worth: A Quarterly Newsletter of the Lifelong Learning Network. Fall 1998, 1, 8 and 9. 
3. Paul, R., 1992. Critical thinking: basic questions and answers. Retrieved 20 March 2010 from http://www.criticalthinking.org/University/question s.html

4. Wegerif, R., B.M. McLaren, M. Chamrada, O. Scheuer, N. Mansour, J. Miksatko and M. Williams, 2010. Exploring creative thinking in graphically mediated synchronous dialogues. Computers and Education, 54: 613-621.

5. Jones, D., 1996. Critical thinking in an online world. Retrieved 20 March 2010 from www.library.ucsb.edu/ untangle/jones.html

6. Martin, K., 1998. Issues of teaching and learning. Retrieved 20 March 2010 from http://www.csd.uwa.edu.au/NEWSLETTER/issues 1 098/staff.htm

7. Galea, S.R., 1999. Apprenticeship in thinking and the adult student. 8th International Conference on Thinking. "Thinking for a Change Society", 5-9 July, Shaw Conference, Edmonton, Alberta, Canada. Retrieved 20 March 2010 from www.digest. myvirtec.net/docs/Shameem1.doc

8. Siddhu, N., 1998. A lesson in critical thinking. The Star, 18 July, 1998.

9. Moore, R.A., 1992. Critical thinking ability and measures of language proficiency: A quantitative study on the X152 seminar for Malaysians. Language Education Department of Indiana University.

10. Kantha, K.R., 2002. The dilemma of promoting reflective practice in higher education: Between rhetoric and reality. In Focusing on the Students. Proceedings of the $11^{\text {th }}$ Annual Teaching Learning Forum, 5-6 February 2002. Perth: Edith Cowan University.

11. Segers, E. and L. Verhoeven, 2009. Learning in a sheltered internet environment: The use of WebQuests. Learning and Instruction, 19: 423-432.

12. Nojey, W.P., 1998. Perceptions of secondary school teachers on the factors, which influence the climate for creativity in schools. Msc. Thesis. University Malaysia Sarawak.
13. NadzrahAbu Bakar, 2007. Factors that contribute to the effective use of computers in the classroom: The Malaysian Context. Asiacall Online Journal, 2(1): 27-33. Retrieved on $3^{\text {rd }}$ March 2013. http://asiacall.org/journals/journal_articles_2006_2 007/NadzrahRevision01.pdf

14. Samuel, Robinson Joseph and Abu Bakar, Zaitun 2006. The utilization and integration of ICT tools in promoting English language teaching and learning: Reflections from English option teachers in Kuala Langat District, Malaysia, International Journal of Education and Development using Information and Communication Technology (IJEDICT), 2(2): 4-14.

15. Jackson, W., 1995. Doing social research methods. Scarborough, Ontario: Prentice Hall Canada Inc.

16. Ennis, R.H. and J. Millman, 1985. Cornell Critical Thinking Test, Level X. ( $3^{\text {rd }}$ ed) Pacific Grove, CA: Midwest Publications.

17. Ennis, R.H., J. Millman and T.N. Tomko, 1985. Cornell Critical Thinking Test, Level $\mathrm{X}$ and Level Z: Manual. ( $3^{\text {rd }}$ ed) Pacific Grove, CA: Midwest Publications.

18. An Academic Achievement Update Report, 2000. Road to accreditation: MCC assessment of the 5 year mile marker. March 1996-January 2000. Retrieved 20 March 2010 from www.kometro.cc.mo.us/ research/RoadtoAcreditation.pdf

19. Dennen, V.P., 2007. Looking for evidence of learning: Assessment and analysis methods for online discourse. Computers in Human Behavior, 24: 205-219.

20. Jonassen, D., 2000. Computers as mindtools for schools: Engaging critical thinking. (2nd ed.). Saddle River, NJ: Prentice Hall, Inc.

21. Ransdell, S., 2010. Online activity, motivation and reasoning among adult learners. Computers in Human Behavior, 26: 70-73.

22. Kozub, R.M., 2010. An ANOVA analysis of the relationship between business students' learning styles and effectiveness of Web-based instruction. American Journal of Business Education, 3(3). 00-00. 